\title{
Predictors of using trains as a suicide method: findings from Victoria,
}

\section{Australia}

Lay San Too ${ }^{a^{*}}$, Lyndal Bugeja ${ }^{b}$, Allison Milner ${ }^{\mathrm{c}, \mathrm{d}}$, Roderick McClure ${ }^{\mathrm{e}}$, Matthew J. Spittal ${ }^{\mathrm{a}}$

${ }^{a}$ Centre for Mental Health, Melbourne School of Population and Global Health, The University of Melbourne, Victoria, Australia

${ }^{b}$ Department of Forensic Medicine, School of Public Health and Preventive Medicine, Monash University, Victoria, Australia

${ }^{c}$ Deakin Population Health SRC, School of Health and Social Development, Deakin University, Victoria, Australia

${ }^{\mathrm{d} C e n t r e}$ for Health Equity, Melbourne School of Population and Global Health, The University of Melbourne, Victoria, Australia

${ }^{\mathrm{e}}$ Harvard Injury Control Research Center, Harvard School of Public Health, Massachusetts, United States.

*Corresponding author:

Lay San Too

Centre for Mental Health

Melbourne School of Population and Global Health

The University of Melbourne

Victoria, 3010, Australia

E-mail: tiffany.too@unimelb.edu.au

Tel: +61 383442722 


\begin{abstract}
This study aimed to investigate the factors associated with the choice of trains over other means of suicide. We performed a case-control study using data on all suicides in Victoria, Australia between 2009 and 2012. Cases were those who died by rail suicide and controls were those who died by suicide by any other means. A logistic regression model was used to estimate the association between the choice of trains and a range of individual-level and neighborhood-level factors. Individuals who were never married had double odds of using trains compared to individuals who were married. Those from areas with a higher proportion of people who travel to work by train also had greater odds of dying by railway suicide compared to those from areas with a relatively lower proportion of people who travel to work by train. Prevention efforts should consider limiting access to the railways and other evidence-based suicide prevention activities.
\end{abstract}

\title{
Keywords
}

Suicide, railway, railroads, Australia 


\section{Introduction}

In Australia, hanging, poisoning by substances, and poisoning by carbon monoxide and other gases were the most frequent used methods of suicide in 2012 (Australian Bureau of Statistics, 2014). However, there is variation in the choice of suicide method across states and territories. For instance, the largest proportion of suicides by jumping in front of a train was found in Victoria, while hanging was more common in Northern Territory, and poisoning by carbon monoxide and other gases was particular prevalent in Western Australia. The current study focused on suicide by train in Victoria, which accounted for approximately $7 \%$ of all suicides in the state (Australian Bureau of Statistics, 2014). This proportion was relatively moderate compared with the global proportion of suicide by train which ranged from $1 \%$ to 12\% of all suicides (Krysinska and De Leo, 2008, Taylor et al., 2016). Although suicide by train is rare, it has been reported as the major cause of death on the rail network in Victoria (Too et al., 2015) and overseas (Mishara, 1999, Rådbo et al., 2005, Gershon et al., 2008, Sousa et al., 2015).

Suicides by train are highly distressing for train drivers and witnesses (Bardon and Mishara, 2015). They can also cause economic losses through the disruption of train services, driver absenteeism, and counseling required for affected individuals (Lukaschek et al., 2011, Mehnert et al., 2012, Silla et al., 2012).

Although suicides by train are a prominent problem within the railway sector, there is limited understanding of the factors associated with an individual's decision to use a train as a method to end one's life (as opposed to other methods). One study interviewed railway suicide survivors and found that nearly half chose trains because they knew of someone else who used this method. Some also perceived this method as quick, highly lethal, easily accessible and/or widely available (O'Donnell et al., 1996). Another study interviewed nine railway suicide survivors and found that the view that jumping in front of a train has a high 
chance of dying and easy access to trains were their reasons for choosing trains (Chowdhury et al., 2000). This is consistent with a large body of work that shows that suicide by particular means is closely linked with the availability of that means (Ajdacic-Gross et al., 2008, Thomas et al., 2011, Yip et al., 2012).

Previous studies comparing suicides by train with suicides by other means have shown, in general, that suicides by train did not differ from suicides by other means in terms of gender, mental health, adverse life events, and local socioeconomic status (Emmerson and Cantor, 1993, Abbot et al., 2003, Silla and Luoma, 2012). However, in one study, nearly 40\% of those who died by rail suicide were found to have some kind of connection with rail (e.g., living close to a railway line, past experience trespassing on rail tracks); whereas, only 7\% suicides by other means had that same relationship (Abbot et al., 2003). There is also evidence that people who died by rail suicide were younger than those who used other suicide means (Emmerson and Cantor, 1993, Silla and Luoma, 2012). Mental health inpatients were more likely to use trains while outpatients were more likely to poison themselves to end their own lives (Huisman et al., 2010). Existing literature on suicides by train showed that the majority of the victims were male, young, never married or single, unemployed or not in the labour force, and have been diagnosed with a mental illness and admitted for mental health care (Mishara, 2007, Ratnayake et al., 2007, Krysinska and De Leo, 2008, van Houwelingen and Kerkhof, 2008).

Because of the small amount of work previously done to uncover the factors associated with the choice of trains over other methods to suicide and none of them were conducted in Australia, this study seeks to examine the factors associated with the choice of a train as a suicide method using data from the country. Improved knowledge about these factors may be useful for informing intervention efforts. Based on the findings from previous research as indicated above, we hypothesized that people who died of suicide by train would 
be different from those who died of suicide by other means on several factors. Those who died of suicide by train would be younger, never married or single, unemployed or not in the labour force, and have a history of mental illness and mental health hospitalization. We also hypothesized that these people would have easier access to trains. It is less clear what the association would be for other factors.

\section{Methods}

\subsection{Study setting and design}

Victoria is the second largest state in Australia. It has a population of approximately 5.7 million people. Most of the Victorians live in Melbourne, the state's capital with a population of 4.1 million. Melbourne is serviced by a metropolitan railway network consisting of 16 railway lines with 230 railway stations. Seventy percent of people from Melbourne who travel to work by public transport use train services (Bureau of Infrastructure Transport and Regional Economic, 2012). Victorian railway tracks are generally constructed at ground level and contain a large number of level crossings. About $90 \%$ of the tracks are unfenced.

We performed a case-control study using four years of coronial data from the state of Victoria, Australia. We compared individuals who died by suicide using a train (cases) to those who died from suicide using all other methods (controls) in order to identify factors associated with using a train as a means of suicide.

\section{$2.2 \quad$ Suicide data}

We obtained data on deaths classified as intentional self-harm (ICD-10 code X60-X84) from the National Coronial Information System (NCIS). The NCIS is a national internet-based data storage and retrieval system of Australian coronial records. For each record, there are four full text reports: the police summary of circumstances, the autopsy report, the toxicology 
report, and the coroner's findings. Each record also contains coded information such as age, sex, marital status, employment status, date of death, and usual residential address. NCIS is regarded as the primary data source for research in injury and death (Victorian State Government, 2015). It offers much more detailed information than the Australian Bureau of Statistics (ABS) and is regarded as a reliable source of suicide figures in Australia (Driscoll et al., 2003).

To overcome the possibility that cases could be missed because the coroners' investigation was complete but not yet uploaded into NCIS, the Coroners Court of Victoria (CCOV) cross-referenced records we identified in NCIS with their own records. As a result, an additional 40 cases for 12 years were identified from CCOV and included. These cases tended to be from more recent years.

We retrieved and reviewed all intentional self-harm deaths coded as X60-X84 (ICD10) (World Health Organization, 2010). We categorised suicides coded as X81 or recorded "rail vehicle" as the object involved in the death as suicides by train and all other suicides as being due to other means, such as suicides by hanging, poisoning, jumping from height, firearm shooting, cutting and so forth.

\subsection{Inclusion and exclusion criteria}

We included all suicides that occurred from 1 January 2009 to 31 December 2012. We excluded cases and controls that: were still under investigation by the coroner on the date of data extraction (8 September 2015) $(n=21)$; had no certain year of death $(n=14)$; with residency outside Victoria $(n=22)$; and had missing information on usual residential postcode or did not have fixed home address $(n=11)$. 


\section{$2.4 \quad$ Exposure variables}

We assessed a number of individual variables in relation to using a train as a suicide means. These were age, sex, marital status, employment status, diagnosed mental illness, history of mental health hospitalisation, history of suicide attempt and blood alcohol concentration. We also included a range of neighbourhood variables in the analyses. They were social fragmentation, socioeconomic status, train-related variables, number of assaults, concentration of alcohol outlets, number of mental health services, and area remoteness. Train-related variables were categorised into three domains (e.g., availability of trains, accessibility to trains and familiarity with trains) based on how they are usually classified in the past literature (Too et al., 2014). All variables used to measure familiarity with trains were a proxy because we were not able to direct measure our sample on their familiarity with trains providing that they were deceased. These variables were selected because they showed some relationships with suicide by train or overall suicide in the existing literature (e.g., most rail suicide victims were male, young, never married, and/or unemployed; social fragmentation has been found as a strong predictor of suicide; neighbourhood socioeconomic deprivation has been associated with an increased risk of suicide in the population) (Kennedy et al., 1999, Taylor et al., 2005, Rehkopf and Buka, 2006, Mishara, 2007, Ratnayake et al., 2007, Krysinska and De Leo, 2008, van Houwelingen and Kerkhof, 2008, Barth et al., 2011, Branas et al., 2011, Giotakos et al., 2012, Congdon, 2013, Mok et al., 2013).

We included all neighbourhood variables at the postcode level and merged them with the residential postcodes of all suicide cases. Based on the postcode-level data from the 2011 Census, the median population size covered by a postcode was 2,660, ranging from 0 to 77,756. The median geographical size of a postcode is 81.2 square kilometres, ranging from 0.2 to 11415.9 . Table 1 shows the descriptions of all included variables, such as year(s) of availability, operational definition and source. The data of these variables were obtained from 
the best possible sources. For examples, individual information about deceased from the NCIS and CCOV, social information from the ABS Census, and train-related information from the railway organisations who managed the relevant datasets. 
Table 1. Details of individual and neighbourhood variables

\begin{tabular}{|c|c|c|c|}
\hline Variable & $\begin{array}{l}\text { Year(s) of } \\
\text { availability }\end{array}$ & Definition & Data source(s) \\
\hline \multicolumn{4}{|l|}{ Individual-level } \\
\hline Sex & 2009-2012 & The biological sex of the deceased. & NCIS \& CCOV \\
\hline Age & 2009-2012 & The age of the deceased at time of death. & NCIS \& CCOV \\
\hline Marital status & 2009-2012 & The marital status of the deceased at time of death. & NCIS \& CCOV \\
\hline Employment status & 2009-2012 & The employment status of the deceased at time of death. & NCIS \& CCOV \\
\hline Mental illness & $2009-2012$ & $\begin{array}{l}\text { This was defined as the deceased having been diagnosed with a mental illness } \\
\text { in the } 12 \text { months prior to the death. This information was based on coronial } \\
\text { findings when the coronial investigation found evidence of a previously } \\
\text { diagnosed mental illness. Mental illness was only recorded as present if it was } \\
\text { diagnosed by an appropriately qualified medical professional. }\end{array}$ & NCIS \& CCOV \\
\hline $\begin{array}{l}\text { Mental health } \\
\text { hospitalisation }\end{array}$ & $2009-2012$ & $\begin{array}{l}\text { This was defined as based on the evidence that the deceased having been } \\
\text { admitted to hospital for mental health treatment during } 12 \text { months before the } \\
\text { death. This information was obtained from the deceased's medical records } \\
\text { where available. }\end{array}$ & NCIS \& CCOV \\
\hline $\begin{array}{l}\text { Previous suicide } \\
\text { attempt }\end{array}$ & $2009-2012$ & $\begin{array}{l}\text { This was defined as the deceased having at least one suicide attempt prior to } \\
\text { the death. This information was recorded in the coronial record, usually } \\
\text { gathered from the deceased's closed family members, relatives, friends or } \\
\text { medical professionals. }\end{array}$ & NCIS \& CCOV \\
\hline $\begin{array}{l}\text { Blood alcohol } \\
\text { concentration } \\
\text { (g/100ml) }\end{array}$ & 2009-2012 & $\begin{array}{l}\text { The amount of blood alcohol detected from toxicology in ante-mortem or } \\
\text { post-mortem. Deceased had positive alcohol reading if blood alcohol } \\
\text { concentration was detected } \geq 0.05 \mathrm{~g} / 100 \mathrm{ml} \text {. }\end{array}$ & NCIS \& CCOV \\
\hline \multicolumn{4}{|l|}{ Neighbourhood-level } \\
\hline Social fragmentation & 2011 & $\begin{array}{l}\text { Congdon's measure of social fragmentation, which was calculated for all } \\
\text { postcodes by summing the z-scores of the following four variables: \% persons }\end{array}$ & ABS Census \\
\hline
\end{tabular}


living alone, \% persons in rented accommodation, \% unmarried persons and \% persons resided in different address 1 year ago.

Socioeconomic

status

Index of Relative

Socio-economic

Disadvantage

(decile)

Index of

Economic

Resources)

(decile)

Train-related factors

Availability of trains

Presence of

railway tracks

Number of trains

(per 10 trains)

Train speed

$(\mathrm{km} / \mathrm{hr})$

Accessibility to

trains

Number of

surveillance units

(per 10 units)
Presence of railway tracks in each postcode. Railway tracks used for tourist and heritage purposes only were excluded.

Average daily number of trains (passenger and freight trains) passing through the level crossing in each postcode.

Average speed (kilometre per hour) which train is allowed to pass through the level crossing in each postcode.

This index summarises the social and economic conditions of people and households in each postcode. High decile indicates a relative lack of disadvantage and low decile indicates a relative greater disadvantage.

This index reflects the financial aspects of relative socioeconomic advantage and disadvantage in each postcode. High decile indicates a relative greater access to economic resources and low decile indicates a relative lack of access to economic resources.$$
\text { crossing in each postcode. }
$$

Number of surveillance unit installed at railway stations and carparks in each postcode.
ABS Census

\section{ABS Census}

\section{Geoscience}

Australia

(MapConnect),

MTM, V/Line

VicTrack

VicTrack

PTV, MTM 


\begin{tabular}{|c|c|c|c|}
\hline $\begin{array}{l}\text { Number of level } \\
\text { crossing }\end{array}$ & 2014 & $\begin{array}{l}\text { Number of level crossing (including pedestrian and road crossing) in each } \\
\text { postcode. }\end{array}$ & VicTrack \\
\hline $\begin{array}{l}\text { Number of } \\
\text { stations }\end{array}$ & 2009-2012 & Number of railway station in each postcode. & PTV, V/Line \\
\hline \multicolumn{4}{|l|}{$\begin{array}{l}\text { Familiarity with } \\
\text { trains }\end{array}$} \\
\hline $\begin{array}{l}\text { Proportion of } \\
\text { people who travel } \\
\text { to work by train }\end{array}$ & 2011 & $\begin{array}{l}\text { \% employed people aged } 15 \text { years and above who travel to work by train in } \\
\text { each postcode. It was calculated as a ratio to the total employed persons. }\end{array}$ & ABS Census \\
\hline $\begin{array}{l}\text { Number of station } \\
\text { patronage (per } \\
1000 \text { persons) }\end{array}$ & 2009-12 & Average daily number of station patronage in each postcode. & PTV, MTM \\
\hline $\begin{array}{l}\text { Number of } \\
\text { pedestrian (per } \\
100 \text { persons) }\end{array}$ & 2014 & $\begin{array}{l}\text { Average daily number of pedestrian passing through the level crossing in each } \\
\text { postcode. }\end{array}$ & VicTrack \\
\hline \multicolumn{4}{|l|}{$\begin{array}{l}\text { Other environmental } \\
\text { factors }\end{array}$} \\
\hline $\begin{array}{l}\text { Number of } \\
\text { assaults (per } 100 \\
\text { assaults) }\end{array}$ & 2009-2012 & Number of assaults (including physical and family assaults) in each postcode. & $\begin{array}{l}\text { Victoria Police } \\
\text { Corporate } \\
\text { Statistics }\end{array}$ \\
\hline $\begin{array}{l}\text { Number of } \\
\text { alcohol outlets } \\
\text { (per } 10 \text { outlets) }\end{array}$ & 2009-2012 & $\begin{array}{l}\text { Number of active alcohol outlets with general, on-premises, packaged liquor } \\
\text { or restaurant and café license in each postcode. }\end{array}$ & VCGLR \\
\hline $\begin{array}{l}\text { Number of mental } \\
\text { health services }\end{array}$ & 2014 & $\begin{array}{l}\text { Number of mental health services (including adult, child and adolescent, aged } \\
\text { person, community support and inpatient services) in each postcode. }\end{array}$ & MHDR \\
\hline Remoteness & 2009-2012 & $\begin{array}{l}\text { Remoteness of a postcode area, classified based on Australian Statistical } \\
\text { Geography Standard (ASGS) } 2011 .\end{array}$ & ABS \\
\hline
\end{tabular}


Abbreviations: MHDR, Mental Health, Drugs \& Regions (division of the Victorian Government Department of Health); MTM, Metro Trains Melbourne; PTV, Public Transport Victoria; VCGLR, Victorian Commission for Gambling and Liquor Regulation. 


\section{$2.5 \quad$ Statistical analysis}

Prior to undertaking our analysis we coded several train-related variables using a procedure recommended by Robertson and colleagues (Robertson et al., 1994). These variables typically had values of either zero (representing no exposure) or a positive number (representing, for example, average train frequency). We therefore entered these variables into the model using two parameters - a parameter to capture the effect when the exposure had a value of zero, and a parameter to capture the same exposure when it has a value greater than zero. This enabled simultaneous estimation of the relationship between the exposure and the outcome when there was no exposure, and estimation of a dose-response relationship between the exposure and the outcome among those who were exposed.

We utilised a logistic regression model to examine the effects of individual and neighbourhood variables on individual choice of a train as a suicide method. Our strategy was to fit a series of models to the data. In the first instance, all variables in Table 1 were individually entered into a model to estimate their association with the use of a train as a suicide method. Statistically significant variables $(p<0.05)$ from these analyses were then introduced into a multivariate model, controlling for socioeconomic status (Steer Davies Gleave, 2011)). All coefficients were exponentiated and interpreted as odds ratios (ORs). All analyses were conducted in Stata 13.1.

\section{Results}

\subsection{Demographic characteristics}

During the study period, 105 suicides by train (5\%) and 1,856 suicides by other methods (95\%) were available for inclusion in the study. Among suicides by train, $66 \%$ were by males and $34 \%$ by females, with a mean age of 37 years [standard deviation (SD) 16 years]. Of 
those suicides by other methods, $77 \%$ were males and the mean age was 46 years (SD $=18$ years).

\subsection{Factors associated with choice of method}

From the univariate analyses, the individual-level variables that were associated with the likelihood of choosing trains over other methods were age, sex and marital status (see Table 2). Males were less likely to die from suicide by train compared to females (OR 0.6, 95\% CI 0.4, 0.9). Individuals who were younger than 35 years old were more likely to use trains to end their own lives compared to individuals who were 60 years and older (OR 3.0, 95\% CI 1.6, 5.6). People who were never married had more than triple the odds of using trains to kill themselves compared to individuals who were married or in de facto relationship (OR 3.3, 95\% CI 2.1, 5.3). All other individual-level variables were unrelated to individual choice of trains as a suicide method. These were employment status, mental illness, history of mental health hospitalisation, previous suicide attempt, and alcohol consumption prior to death.

With respect to the neighbourhood level variables, individuals who lived in an area with a presence of railway tracks were more likely to die by suicide on the railways than those who lived in an area without a presence of railway tracks (OR 1.9, 95\% CI 1.1, 3.1, see

Table 3). Those who lived in an area with higher frequency of train services also had greater odds of choosing trains to end their lives compared to those who lived in an area with relatively lower frequency of train services (OR 1.03, 95\% CI 1.01, 1.06). A similar relationship was found for the number of railway stations. Those people who lived in an area with a higher number of railway stations had increased odds of selecting trains as their suicide method compared with those who lived in an area with relatively lower number of railway stations (OR 1.3, 95\% CI 1.1, 1.5). People who were from an area with a higher proportion of people who travel to work by train had heightened odds of suicide by train (OR 
1.04, 95\% CI 1.02, 1.06). Lastly, those who lived in a city area had approximately triple the odds of killing themselves using trains compared to those who lived in a regional or remote area (OR 2.6, 95\% CI 1.5, 4.5).

The variables associated with rail suicide in univariate analyses were subsequently assessed jointly in a multivariate model. We also controlled for socioeconomic status at this step. Because three of the variables from the univariate analysis were significantly correlated: (1) train frequency; (2) number of stations; and (3) proportion of people who travel to work by train, $[r(1 \& 2)=0.6, r(1 \& 3)=0.6$, and $r(2 \& 3)=0.7]$, we used only the variable of proportion of people who travel to work by train in our analysis on the grounds that it had a stronger association with suicides by train and is a more direct measure of the use of rail services (i.e. the proportion of people who use train) than the other two variables. 
Table 2. Descriptive and univariate results at individual level

\begin{tabular}{|c|c|c|c|c|c|}
\hline Variable & $\begin{array}{l}\text { Cases } \\
\text { n(\%) }\end{array}$ & $\begin{array}{l}\text { Controls } \\
\text { n(\%) }\end{array}$ & Unadjusted OR & $95 \% \mathrm{CI}$ & p-value \\
\hline Sex & & & & & 0.010 \\
\hline Male & 69 (65.7) & $1,425(76.8)$ & 0.58 & $0.38-0.88$ & \\
\hline Female* & $36(34.3)$ & $431(23.2)$ & 1.00 & & \\
\hline Age (years) & & & & & $<0.001$ \\
\hline$\leq 34$ & $55(52.4)$ & $544(29.3)$ & 3.02 & $1.63-5.60$ & \\
\hline $35-39$ & $37(35.2)$ & $924(49.8)$ & 1.20 & $0.63-2.27$ & \\
\hline$\geq 60^{*}$ & $13(12.4)$ & 388 (20.9) & 1.00 & & \\
\hline Marital status & & & & & $<0.001$ \\
\hline Married (including de facto)* & $33(32.7)$ & $636(41.8)$ & 1.00 & & \\
\hline Never married & $49(48.5)$ & $283(18.6)$ & 3.34 & $2.10-5.30$ & \\
\hline Widowed & $1(1.0)$ & 75 (4.9) & 0.26 & 0.03-1.91 & \\
\hline Divorced & $6(5.9)$ & $149(9.8)$ & 0.78 & $0.32-1.89$ & \\
\hline Separated & $12(11.9)$ & $377(24.8)$ & 0.61 & $0.31-1.20$ & \\
\hline Employment status & & & & & 0.933 \\
\hline Employed* & $41(43.2)$ & 765 (41.7) & 1.00 & & \\
\hline Unemployed & $22(23.2)$ & $454(24.7)$ & 0.90 & $0.53-1.54$ & \\
\hline Not in the labour force & $32(33.7)$ & $616(33.6)$ & 0.97 & $0.60-1.56$ & \\
\hline Mental illness & & & & & 0.116 \\
\hline No diagnosis* & $42(40.0)$ & 889 (47.9) & 1.00 & & \\
\hline At least one diagnosis & $63(60.0)$ & $967(52.1)$ & 1.38 & $0.92-2.06$ & \\
\hline Mental health hospitalization & & & & & 0.118 \\
\hline No* & $79(75.2)$ & $1,511(81.4)$ & 1.00 & & \\
\hline Yes & $26(24.8)$ & $345(18.6)$ & 1.44 & $0.91-2.28$ & \\
\hline
\end{tabular}


Previous attempt

$$
\begin{aligned}
& \text { No* } \\
& \text { At least once }
\end{aligned}
$$

65 (61.9)

40 (38.1)

1,169 (63.0)

1.00

Blood alcohol concentration

$687(37.0)$

1.05

$0.70-1.57$

(g/100ml)
No detected*
82 (78.1)
1,260 (67.9)
1.00
$<0.05$
7 (6.7)
129 (7.0)
0.83
467 (25.2)
0.53
0.38-1.84
16 (15.2)

*Reference category. Marital status was missing for $17.3 \%$, employment status for $1.6 \%$ of all suicides.

\begin{tabular}{|c|c|c|c|c|c|}
\hline Variable & $\begin{array}{l}\text { Cases } \\
\text { n(\%)/mean(SD) }\end{array}$ & $\begin{array}{l}\text { Controls } \\
\text { n(\%)/mean(SD) }\end{array}$ & Unadjusted OR & $95 \% \mathrm{CI}$ & p-value \\
\hline Social fragmentation (z-scores) & $1.8(3.1)$ & $1.5(3.0)$ & 1.03 & $0.97-1.10$ & 0.345 \\
\hline \multicolumn{6}{|l|}{ Socioeconomic status } \\
\hline $\begin{array}{l}\text { Index of Relative Socio-economic } \\
\text { Disadvantage }\end{array}$ & $6.5(2.9)$ & $5.9(2.9)$ & 1.07 & $1.00-1.15$ & 0.057 \\
\hline Index of Economic Resources & $5.3(2.9)$ & $5.1(2.9)$ & 1.03 & 0.96-1.10 & 0.370 \\
\hline Yes & 87 (82.9) & $1,313(72.3)$ & 1.85 & $1.10-3.10$ & \\
\hline No* & $18(17.1)$ & $502(27.7)$ & 1.00 & & \\
\hline Number of trains (per 10 trains) & $9.4(8.8)$ & $6.3(8.4)$ & 1.03 & $1.01-1.06$ & 0.005 \\
\hline Train speed $(\mathrm{km} / \mathrm{hr})$ & $62.1(43.2)$ & $56.3(48.7)$ & 1.00 & $0.99-1.00$ & 0.518 \\
\hline Accessibility to trains & & & & & \\
\hline
\end{tabular}

Table 3. Descriptive and univariate results at neighbourhood level 


\begin{tabular}{|c|c|c|c|c|c|}
\hline Number of surveillance units (per 10 units) & $2.4(4.9)$ & $1.9(4.7)$ & 1.00 & 0.96-1.04 & 0.884 \\
\hline Number of level crossings & $4.2(4.7)$ & $3.9(5.5)$ & 0.99 & $0.95-1.03$ & 0.652 \\
\hline Number of stations & $1.5(1.3)$ & $1.0(1.2)$ & 1.27 & $1.06-1.51$ & 0.008 \\
\hline \multicolumn{6}{|l|}{ Familiarity with trains } \\
\hline $\begin{array}{l}\text { Proportion of people who travel to work by } \\
\text { train }\end{array}$ & $16.3(10.5)$ & $11.2(9.9)$ & 1.04 & $1.02-1.06$ & $<0.001$ \\
\hline $\begin{array}{l}\text { Number of station patronage (per } 1000 \\
\text { persons) }\end{array}$ & $2.1(1.3)$ & $1.6(4.0)$ & 1.01 & 0.96-1.06 & 0.768 \\
\hline Number of pedestrian (per 100 persons) & $3.9(5.8)$ & $3.3(6.1)$ & 1.00 & $0.97-1.03$ & 0.826 \\
\hline \multicolumn{6}{|l|}{ Dther contextual variables } \\
\hline Number of assaults (per 100 assaults) & $2.1(2.5)$ & $2.0(2.4)$ & 1.01 & 0.94-1.10 & 0.735 \\
\hline Number of alcohol outlets (per 10 outlets) & $4.6(9.5)$ & $4.3(8.7)$ & 1.00 & 0.98-1.02 & 0.736 \\
\hline Number of mental health services & $2.0(3.1)$ & $1.8(2.7)$ & 1.03 & $0.96-1.10$ & 0.394 \\
\hline \multicolumn{6}{|l|}{ Remoteness } \\
\hline Urban & $90(85.7)$ & 1,269 (69.9) & 2.58 & $1.48-4.50$ & $<0.001$ \\
\hline Regional/remote* & $15(14.3)$ & $546(30.1)$ & 1.00 & & \\
\hline
\end{tabular}

*Reference category. The number of surveillance units was missing for $17.4 \%$, the number of station patronage was missing for $20.4 \%$, and other area variables were missing for less than $2.5 \%$ of all suicides. 
The final model showed that only two variables remained associated with the choice of trains over other suicide means after adjustment for the other variables in the model (Table 4). Individuals who were never married had greater odds of suicides using trains over other suicide methods compared to individuals who were married or in de facto relationship (OR 2.4, 95\% CI 1.4, 4.1). The odds of choosing trains as a suicide method were also higher in individuals from areas with a higher proportion of train commuters than those from areas with a relatively lower proportion of the measure (OR 1.03, 95\% CI 1.00, 1.06).

Table 4. Multivariate results, controlling for local socioeconomic status

\begin{tabular}{|c|c|c|c|}
\hline Variable & Adjusted OR & $95 \% \mathrm{CI}$ & p-value \\
\hline \multicolumn{4}{|l|}{ Individual-level } \\
\hline Sex & & & 0.099 \\
\hline Male & 0.68 & $0.43-1.07$ & \\
\hline Female* & 1.00 & & \\
\hline Age (years) & & & 0.191 \\
\hline$\leq 34$ & 1.62 & $0.79-3.29$ & \\
\hline $35-39$ & 1.05 & $0.53-2.06$ & \\
\hline$\geq 60^{*}$ & 1.00 & & \\
\hline Marital status & & & $<0.001$ \\
\hline Married (including de facto)* & 1.00 & & \\
\hline Never married & 2.40 & $1.42-4.06$ & \\
\hline Widowed & 0.25 & $0.03-1.96$ & \\
\hline Divorced & 0.75 & $0.30-1.86$ & \\
\hline Separated & 0.60 & $0.30-1.20$ & \\
\hline \multicolumn{4}{|l|}{ Neighbourhood-level } \\
\hline Presence of railway tracks & & & 0.221 \\
\hline Yes & 1.46 & $0.79-2.70$ & \\
\hline No* & 1.00 & & \\
\hline $\begin{array}{l}\text { Proportion of people who travel to } \\
\text { work by train }\end{array}$ & 1.03 & $1.00-1.06$ & 0.023 \\
\hline Remoteness & & & 0.407 \\
\hline Urban & 1.34 & $0.67-2.70$ & \\
\hline Regional/remote* & 1.00 & & \\
\hline
\end{tabular}

*Reference category. 


\section{Discussion}

\subsection{Main findings}

We found that being never married was a key factor for choosing trains over other suicide methods, while living in an area with high proportion of people who use train as the transport to work was an important neighbourhood factor associated with the choice of trains. As opposed to our hypothesis, age, sex, employment status, mental health-related variables, history of previous attempt, alcohol consumption, social and environmental variables, and other train-related variables (e.g. easy access to and high availability of trains) were not associated with the choice of trains as a means of suicide. Reasons for this are unclear, but the most likely explanation was a lack of statistical power. Suicide is a relatively rare event and suicide by train even more so.

\subsection{Strengths and limitations of the study}

Our work is strengthened by including a wide range of individual- and neighbourhood-level factors that have not previously been investigated. However, our work has several limitations. First, under-reporting of suicides is possible due to coronial investigations still being open despite the long follow-up time (this is common in suicides which can be complex to investigate) and misclassification of suicides as undetermined intent or unintentional cause of death (Australian Bureau of Statistics, 2007). We have tried to minimise the first limitation by allowing a long follow-up time (three years) for cases to be closed; the other limitation is difficult to fix. Second, there was a small proportion of deceased persons $(n=5)$ who have their temporary residence recorded as usual residence (e.g., psychiatric hospital). If the psychiatric hospital where the deceased provisionally resided was close to the railways, such inclusion may influence the effects of some train-related factors on the outcome measure; however, this is unlikely to have considerable impact on the key findings. Third, when area- 
level data was not available for the whole study period, we used the data that closest to the year of death. For example, 2011 census data was used for suicides in 2009, 2010 and 2012. We assume these data stay constant across non-data years.

Fourth, because our sample comprised people who were deceased, we were unable to directly measure their familiarity with trains and thus used the proxy of this measure such as proportion of people who travel to work by train. As such, higher proportion of this variable does not necessarily infer that railway suicide deceased travelled to work by train and therefore were familiar with trains. Fifth, we did not have data on whether the deceased knew someone else who used trains to kill themselves. This exposure may be a key factor that affects the choice of a train as a suicide method. Finally, we excluded those who did not have fixed home address or were homeless. Due to these people may have their temporary shelter near to railway tracks and thus have easy access to the tracks, exclusion of these individuals may have weakened the relationships between some train-related factors and the odds of choosing trains to suicide.

\subsection{Interpretation}

In this study of people who had all died by suicide, our focus was to understand the factors associated with individual choice of trains over other suicide methods. Consistent with our hypothesis, our work shows that people who were never married were more likely to choose trains rather than other suicide methods. This is consistent with the past studies undertaken in the United States, Australia and Canada, indicating the majority of train suicide victims were never married at the time of death (Mishara, 1999, De Leo and Krysinska, 2008, Berman et al., 2014). One possible interpretation could be people who are never married may be less likely to own a car and therefore more likely to use a train as their transport in day-to-day life compared with people who are married (especially those who have young children). For this 
reason, people who are never married may be more familiar with trains (e.g., trains schedules and railway environments) than people who are married. Nevertheless, the mechanism for why individuals who were never married tended to choose trains over other suicide means is unknown.

The above interpretation is supported by another finding from this work. We found that many individuals who chose a train rather than other means as a suicide method were from areas where a high proportion of people who travel to work by train. This factor is a proxy indicator of familiarity with trains. We therefore argue that individuals who died from suicide by train may be more familiar with trains than those who died from suicides by other means. This argument is supported by one of Durkheim's propositions (Durkheim, 18581917/1951), that people are inclined to use the means of suicide that is made familiar to them by daily use. This is also supported by a previous study showing that individuals who died from suicide by train were more familiar with rail compared to those who died from suicide by other means (Abbot et al., 2003). So, it may be that those who chose trains as means to suicide may have been more familiar with trains (although we acknowledge that we did not have the data to examine this).

Our findings somewhat contradict the literature (Ajdacic-Gross et al., 2008, Yip et al., 2012) and our hypothesis in that we found no significant link between availability of/accessibility to trains and the choice of a train as a suicide means, after adjusting for other variables in the multivariate model. This suggests that familiarity with suicide method may be a stronger factor for the method choice compared to availability of/accessibility to suicide method. However, it seems to be impossible to decrease people's familiarity with trains because train is a known public transportation and it is difficult to directly measure this variable. The significant results of availability of/accessibility to trains from the univariate models indicated that these factors played some roles in the choice of trains, though with 
weaker effects compared to familiarity with trains. Therefore, strategies to restrict means (i.e., limiting access to the railway tracks) should be considered because this intervention has been proven to effectively reduce suicides by train in countries like Hong Kong and Japan (Law et al., 2009, Ueda et al., 2015).

Apart from the abovementioned differences, our work shows that suicides by train and suicides by other methods did not significantly distinguish in many aspects of individual and neighbourhood characteristics, despite existing literature documented that individuals who died by train were predominantly with males, young adults, and people who had at least one diagnosed mental illness (Mishara, 2007, Ratnayake et al., 2007, Krysinska and De Leo, 2008, van Houwelingen and Kerkhof, 2008). Our findings are similar to the findings from a descriptive study conducted in England, where gender, mental health, adverse life events, and local socioeconomic status were not significantly different between suicides by train and suicides by other methods (Abbot et al., 2003). These findings might be a reflection of the fact that there were a small number of suicides by train and thus a lack of statistical power. We suggest that our study should be replicated in other countries to assess the robustness of our findings. Nevertheless, based on the similarities between the characteristics of suicides by train and those of suicides by other means, we propose that prevention efforts should also consider strategies that can reduce suicides by all means such as engaging key relevant stakeholders, raising awareness that suicides are preventable using public campaigns, and promoting help-seeking (World Health Organization, 2014) as this may lead to a decrease in suicides by train.

\section{Conclusions}

This study shows that individual choice of trains over other suicide methods may be primarily determined by familiarity with trains. This factor has a stronger effect on suicide method 
choice than availability of/accessibility to means. Prevention strategies should focus on limiting access to the railways as well as the efforts to reduce overall suicides because these may reduce the tragic events of suicides by train. 


\section{Acknowledgements}

The authors would like to thank the Department of Justice and Regulation for granting access to the National Coronial Information System, the Coroners Court of Victoria for crossreferencing railway suicide data, and Ms Nadia Polikarpowski (NCIS Coder at the Coroners Court of Victoria) for her assistance in data collection. We also thank the Victorian railway regulators and operators (from the Department of Transport, Planning \& Local Infrastructure, Public Transport Victoria, Victrack, Metro trains, V/Line, Australian Rail Track Corporation and Transport Safety Victoria), the Australian Bureau of Statistic, Victorian Commission for Gambling and Liquor Regulation and the Victoria Police for providing data.

\section{Authors' contributions}

All authors participated in the design of the study. LST collected data with support from LB. LST performed the statistical analyses with input from MJS, AM and RM. LST prepared the first draft of the paper. All authors revised the draft and contributed to the final version of manuscript.

\section{Funding}

This research did not receive any specific grant from funding agencies in the public, commercial, or not-for-profit sectors.

\section{Conflict of interest}

None. 


\section{Ethical approval}

This study received full ethical approval from the Health Sciences Human Ethics Committee

(the University of Melbourne) and the Justice Human Research Ethics Committee (State Government Victoria). 


\section{References}

Abbot, R., Young, S., Grant, G., Goward, P., Seager, P., Ludlow, J., 2003. Railway suicide: an investigation of individual and organizational consequences. Doncaster and South Humber Healthcare NHS Trust, Doncaster, UK.

Ajdacic-Gross, V., Weiss, M. G., Ring, M., Hepp, U., Bopp, M., Gutzwiller, F., Rössler, W., 2008. Methods of suicide: international suicide patterns derived from the WHO mortality database. Bulletin of the World Health Organization 86, 726.

Australian Bureau of Statistics, 2007. Information paper: external causes of death, data quality, 2005. Cat. no. 3317.0.55.001. Australian Bureau of Statistics, Canberra.

Australian Bureau of Statistics, 2014. Causes of death, Australia, 2012. Cat. no. 3303.0. Australian Bureau of Statistics: Canberra.

Bardon, C., Mishara, B. L., 2015. Systematic review of the impact of suicides and other critical incidents on railway personnel. Suicide and Life-Threatening Behavior 45, 720-731.

Barth, A., Sogner, L., Gnambs, T., Kundi, M., Reiner, A., Winker, R., 2011. Socioeconomic factors and suicide: an analysis of 18 industrialized countries for the years 1983 through 2007. Journal of Occupational and Environmental Medicine 53, 313-317.

Berman, A. L., Sundararaman, R., Price, A., Au, J. S., 2014. Suicide on railroad rights-ofway: a psychological autopsy study. Suicide and Life-Threatening Behavior 44, 710722.

Branas, C. C., Richmond, T. S., Ten Have, T. R., Wiebe, D. J., 2011. Acute alcohol consumption, alcohol outlets, and gun suicide. Substance Use and Misuse 46, 15921603. 
Bureau of Infrastructure Transport and Regional Economic, 2012. Understanding Australia’s urban railways, research report 131. Bureau of Infrastructure Transport and Regional Economics: Canberra.

Callanan, V. J., Davis, M. S., 2012. Gender differences in suicide methods. Social Psychiatry and Psychiatric Epidemiology 47, 857-869.

Chowdhury, A. N., Dutta, S., Chowdhury, S., 2000. Eco-psychiatry: Suicidal behaviour at Calcutta metro rail: a prospective study. International Medical Journal 7, 27-32.

Congdon, P., 2013. Assessing the impact of socioeconomic variables on small area variations in suicide outcomes in England. International Journal of Environmental Research and Public Health 10, 158-177.

De Leo, D., Krysinska, K., 2008. Suicidal behaviour by train collision in Queensland, 19902004. The Australian and New Zealand journal of psychiatry 42, 772-779.

Driscoll, T., Henley, G., Harrison, J., 2003. The National Coroners Information System as an information tool for injury surveillance. Catalogue no. INJCAT 60. Australian Institute of Health and Welfare, Canberra.

Durkheim, E., 1858-1917/1951. Suicide: a Study in Sociology by Emile Durkheim. The Free Press, Glencoe, IL.

Emmerson, B., Cantor, C., 1993. Train suicides in Brisbane, Australia, 1980-1986. Crisis 14, $90-94$.

Gershon, R. R. M., Pearson, J. M., Nandi, V., Vlahov, D., Bucciarelli-Prann, A., Tracy, M., Tardiff, K., Galea, S., 2008. Epidemiology of subway-related fatalities in New York City, 1990-2003. Journal of Safety Research 39, 583-588.

Giotakos, O., Tsouvelas, G., Kontaxakis, V., 2012. Suicide rates and mental health services in Greece. Psychiatriki 23, 29-38. 
Huisman, A., van Houwelingen, C. A. J., Kerkhof, A. J. F. M., 2010. Psychopathology and suicide method in mental health care. Journal of Affective Disorders 121, 94-99.

Kamizato, E., Yoshitome, K., Yamamoto, Y., Iwase, T., Tsuda, T., Miyaishi, S., Doi H., 2009. Factors affecting the choice of suicide method in Okayama: a database analysis from a forensic perspective. Acta Medica Okayama 63, 177-186.

Kanchan, T., Menon, A., Menezes, R. G., 2009. Methods of choice in completed suicides: gender differences and review of literature. Journal of Forensic Sciences 54, 938-942.

Kennedy, H. G., Iveson, R. C., Hill, O., 1999. Violence, homicide and suicide: strong correlation and wide variation across districts. British Journal of Psychiatry 175, 462466.

Krysinska, K., De Leo, D., 2008. Suicide on railway networks: epidemiology, risk factors and prevention. The Australian and New Zealand journal of psychiatry 42, 763-771.

Law, C. K., Yip, P. S. F., Chan, W. S. C., Fu, K. W., Wong, P. W. C., Law, Y. W., 2009. Evaluating the effectiveness of barrier installation for preventing railway suicides in Hong Kong. Journal of Affective Disorders 114, 254-262.

Lukaschek, K., Baumert, J., Ladwig, K. H., 2011. Behaviour patterns preceding a railway suicide: Explorative study of German Federal Police officers' experiences. BMC Public Health 11:620.

Mehnert, A., Nanninga, I., Fauth, M., Schäfer, I., 2012. Course and predictors of posttraumatic stress among male train drivers after the experience of 'person under the train' incidents. Journal of Psychosomatic Research 73, 191-196.

Mishara, B. L., 1999. Suicide in the Montreal subway system: characteristics of the victims, antecedents, and implications for prevention. Canadian Journal of Psychiatry 44, 690696. 
Mishara, B. L., 2007. Railway and metro suicides: understanding the problem and prevention potential. Crisis 28, 36-43.

Mok, P. L., Leyland, A. H., Kapur, N., Windfuhr, K., Appleby, L., Platt, S. \& Webb, R. T., 2013. Why does Scotland have a higher suicide rate than England? An area-level investigation of health and social factors. Journal of Epidemiology and Community Health 67, 63-70.

O'Donnell, I., Farmer, R., Catalán, J., 1996. Explaining suicide: the views of survivors of serious suicide attempts. British Journal of General Practice 168, 780-786.

Rådbo, H., Svedung, I., Andersson, R., 2005. Suicides and other fatalities from train-person collisions on Swedish railroads: a descriptive epidemiologic analysis as a basis for systems-oriented prevention. Journal of Safety Research 36, 423-428.

Ratnayake, R., Links, P. S., Eynan, R., 2007. Suicidal behaviour on subway systems: a review of the epidemiology. Journal of Urban Health 84, 766-781.

Rehkopf, D. H., Buka, S. L., 2006. The association between suicide and the socio-economic characteristics of geographical areas: a systematic review. Psychological Medicine 36, 145-157.

Robertson, C., Boyle, P., Hsieh, C. C., Macfarlane, G. J., Maisonneuve, P., 1994. Some statistical considerations in the analysis of case-control studies when the exposure variables are continuous measurements. Epidemiology 5, 164-170.

Silla, A., Luoma, J., 2012. Main characteristics of train-pedestrian fatalities on Finnish railroads. Accident Analysis and Prevention 45, 61-66.

Sousa, S., Santos, L., Dinis-Oliveira, R. J., Magalhaes, T., Santos, A., 2015. Pedestrian fatalities resulting from train-person collisions. Traffic Injury Prevention 16, 208-212.

Stack, S., Wasserman, I., 2005. Race and method of suicide: culture and opportunity. Archives of Suicide Research 9, 57-68. 
Steer Davies Gleave, 2011. The Value of Station Investment: Research on Regenerative Impacts. Network Rail, London, UK.

Taylor, A. K., Knipe, D. W., Thomas, K. H., 2016. Railway suicide in England and Wales 2000-2013: a time-trends analysis. BMC Public Health 16, 270.

Taylor, R., Page, A., Morrell, S., Harrison, J., Carter, G., 2005. Mental health and socioeconomic variations in Australian suicide. Social Science and Medicine 61, 15511559.

Thomas, K., Chang, S. S., Gunnell, D., 2011. Suicide epidemics: the impact of newly emerging methods on overall suicide rates - a time trends study. BMC Public Health $11,314$.

Too, L. S., Milner, A., Bugeja, L., McClure, R., 2014. The socio-environmental determinants of railway suicide: a systematic review. BMC Public Health 14, 1-10.

Too, L. S., Spittal, M. J., Bugeja, L., Milner, A., Stevenson, M., McClure, R., 2015. An investigation of neighborhood-level social, economic and physical factors for railway suicide in Victoria, Australia. Journal of Affective Disorders 183, 142-148.

Ueda, M., Sawada, Y., Matsubayashi, T., 2015. The effectiveness of installing physical barriers for preventing railway suicides and accidents: evidence from Japan. Journal of Affective Disorders 178, 1-4.

van Houwelingen, C. A. J., Kerkhof, A. J. F. M., 2008. Mental healthcare status and psychiatric diagnoses of train suicides. Journal of Affective Disorders 107, 281-284.

Varnik, A., Kolves, K., van der Feltz-Cornelis, C. M., Marusic, A., Oskarsson, H., Palmer, A., Reisch, T., Scheerder, G., Arensman, E., Aromaa, E., Giupponi, G., Gusmäo, R., Maxwell, M., Pull, C., Szekely, A, Sola, V. P., Hegerl, U., 2008. Suicide methods in Europe: a gender-specific analysis of countries participating in the "European Alliance Against Depression". Journal of Epidemiology and Community Health 62, 545-551. 
Victorian State Government, 2015. National Coronial Information System (NCIS) annual report 2014-15. National Coronial Information System, Victoria.

World Health Organization, 2010. International Statistical Classification of Diseases and Related Health Problems 10th Revision. World Health Organization, Geneva.

World Health Organization, 2014. Preventing suicide: a global imperative. World Health Organization, Geneva.

Yip, P. S. F., Caine, E., Yousuf, S., Chang, S.-S., Wu, K. C.-C., \& Chen, Y.-Y., 2012. Means restriction for suicide prevention. The Lancet 379, 2393-2399. 